\title{
SOLUSI STRATEGIS ORGANISASI BISNIS MENGHADAPI PERSAINGAN DI ERA GLOBAL
}

\author{
Salim Al Idrus \\ Fakultas Ekonomi Universitas Islam Negeri (UIN) Malang \\ J1. Gajayana No. 50, Telepon (0341) 558881, Fax. (0341) 558881, \\ E-mail: feuinmlg@yahoo.co.id
}

\begin{abstract}
Have been creating shift and new paradigm. The change of science and technology, economy, politic, social, value and culture, market and environment are impetus in creating thight competition. These latter condition require every company to do a transformation in its activity in order to be more efficient and competitive. The company must follow, adjust and make the use of every chance and challenge caused by the changes. The greater world's development, the greater the need of adaptation ability. In related with economic activity, pragmatism consideration needs to be considered. It means that every company is required to obsrever world's development comprehensively. As one of the economic power, a company must compete with other player in open and complex competition.
\end{abstract}

Keywords: business organization, globalization, activity transformation

Beberapa kecenderungan global yang mempunyai dampak langsung bagi perkembangan bisnis telah menimbulkan beberapa fenomena yang perlu diantisipasi oleh pelaku bisnis yang terlibat di dalamnya. Pertama, terjadinya perluasan ekonomi yang telah menyebabkan ketidakstabilan, dimana kemampuan produksi di setiap negara cenderung meningkat setiap tahunnya. Kedua, karena kecanggihan teknologi, maka kebutuhan dunia industri terhadap tenaga kerja semakin mengecil. Ini dikarenakan banyak tenaga manusia yang digantikan tenaga mesin. Akibatnya, masalah-masalah sosial timbul berbarengan dengan semakin majunya tingkat perekonomian seluruh bangsa.

Globalisasi juga menghadirkan "kekacauan" perubahan dengan intensitas yang sedemikian cepat. Oleh karena itu, setiap perusahaan dituntut keluwesannya dalam mengantisipasi perubahan yang cepat itu. Penyesuaian gaya manajemen dengan ekonomi pasar yang telah menjadi trend umum penting dikedepankan. Manajemen konvensional dengan 
tingkat pengambilan keputusan yang rumit sudah saatnya untuk diganti dengan yang lebih sesuai.

Tantangan-tantangan persaingan global mempunyai implikasi bagi bisnis, bahwa kapasitas organisasi merupakan satu-satunya senjata kompetitif. Ulrich (1998) menyatakan bahwa bentuk-bentuk persaingan tradisional yang mengandalkan pada keunggulankeunggulan seperti efisiensi biaya, kemajuan teknologi, kecepatan distribusi, efisiensi produksi dan pengembangan karakteristik produk, cepat atau lambat dapat ditiru oleh pesaing. Oleh karena itu, di era persaingan global yang hyper competition, maka untuk memenangkan persaingan dapat dilakukan dengan meningkatkan kapasitas baru organisasi melalui keunggulan organisasi seperti kecepatan, kemampuan daya tanggap, kelincahan atau kegesitan, kemampuan pembelajaran dan kompetensi (Ulrich, 1998).

Bagi perusahaan yang bergerak di lingkungan global perubahan dan penyesuaian merupakan sesuatu yang tak terelakkan, semua ini ditujukan bagi kesinambungan dan kemampuan bersaing dengan pelaku-pelaku ekonomi lain. Tujuan dari perubahan pada hakikatnya ada dua (Robbins, 1996). Pertama, perubahan itu mengupayakan perbaikan kemampuan organisasi untuk menyesuaikan diri terhadap perubahan dalam lingkungan. Kedua, perubahan itu mengupayakan perubahan perilaku karyawan. Oleh karena itu, dalam upaya penyesuaian tersebut, solusi strategis berikut cukup layak untuk dicermati.

\section{Perubahan Struktur Organisasi dan Kapabilitas Organisasional}

Perubahan menghadapi tantangan-tantangan bisnis kritis mengharuskan organisasi menciptakan kapabilitas baru organisasional untuk mencapai keunggulan organisasi. Upaya untuk mencapai keunggulan ini, nampaknya di masa yang akan datang akan menjadi tanggung jawab dan kesempatan bagi sumber daya manusia untuk memainkan peran kepemimpinan dalam organisasi yang memungkinkan untuk memenuhi tantangan kompetitif. Ulrich (1998) menyatakan ada beberapa tantangan kompetitif yang secara bersama-sama mengharuskan organisasi untuk membangun kapabilitas baru, yaitu globalisasi, kemampuan mendapat laba melalui pertumbuhan, modal intelektual, dan perubahan yang tidak pernah berhenti dan berlangsung dengan cepat.

Tantangan yang demikian itu, mengharuskan produksi lebih adaptif dan berupaya mengembangkan kapabilitas organisasional sebagai alat kompetitif melalui keunggulan organisasi seperti kecepatan, kemampuan daya tanggap, kelincahan atau kegesitan, 
kemampuan pembelajaran dan kompetensi karyawan. Pengembangan kapabilitas organisasional mengharuskan pihak manajemen untuk proaktif melalui proses transformasi organisasional, baik transformasi organisasi atau restrukturisasi yang meliputi struktur, kultur sistem maupun transformasi kualitas proses dan aktivitas.

Proses rasionalisasi dan spesialisasi yang bermula dari masa revolusi industri telah mendorong terciptanya struktur organisasi hierarkis, mekanistik, otokratik, konfrontatif yang terlancur menjadi tinggi dan gemuk. Dalam menghadapi gejolak perubahan, struktur organisasi tradisional yang demikian menjadi terlalu kaku dan tidak mampu beradapatasi dari dalam untuk berkembang.

Snow \& Miles (1996) menunjukkan bahwa pengembangan dalam organisasi bergeser dari struktur organisasi tradisional: functional, divisional, matrix ke struktur organisasi modern: network, celluler. Struktur organisasi network memiliki struktur yang lebih datar dan struktur organisasi celluler merupakan struktur di masa yang akan datang, tidak melibatkan hierarki manajemen. Untuk itu perlu merancang kembali sifat dasar dan bentuk struktur internalnya secara radikal dan dramatis dalam upaya untuk meningkatkan fleksiblitas, kecepatan, daya tanggap terhadap berbagai perubahan lingkungan.

Perusahaan harus mengubah cara mengelola organisasinya agar lebih kompetitif dengan berusaha keras melakukan berbagai praktik manajemen yang lebih fleksibel, dengan tingkat manajemen yang datar dan jumlah karyawan yang lebih sedikit (Walker, 1993). McDermott (1996) menyatakan bahwa organisasi yang berkinerja tinggi dewasa ini adalah sebagai usaha untuk memenuhi tuntutan-tuntutan:

- Peningkatan rasa kepemilikan atau tanggung jawab di antara para karyawan untuk menyampaikan service atau product secara kompetitif.

- Keterlibatan dan pemberdayaan karyawan di seluruh organisasi.

- Kecepatan, kemampuan daya tanggap, kualitas dan kepuasan pelanggan.

Dengan demikian menurut McDermott, sebagai reaksi terhadap tuntutan-tuntutan ini, maka organisasi harus lebih berkarakteristik pada:

- Kerjasama team

- Struktur organisasi flat dengan spans of control yang lebih luas

- Proses yang berfokus pada pelanggan

- Temporary particpatory units yang dilibatkan dalam design policy dan strategi 
Pembahasan di atas menunjukkan terjadinya berbagai bentuk transformasi organisasi. Transformasi kualitas dan proses dengan penekanan pada peningkatan kualitas dan perancangan ulang yang berorientasi pada kepuasan pelanggan. Pergeseran paradigma yang muncul ini berdampak pada bentuk organisasi. Transformasi organisasi atau restrukturisasi yang meliputi bentuk struktur, kultur dan sistem yang mempunyai penekanan yang berbeda dengan bentuk sebelumnya. Dan menghendaki suatu organisasi yang fleksibel, cepat dan memiliki daya tanggap. Tabel 1 menjelaskan perubahan karakteristik organisasi sebagai tuntutan terhadap kapabilitas organisasional.

\section{Tabel 1. Perubahan Karakteristik Organisasi}

\begin{tabular}{|c|c|}
\hline Dari & \\
\hline $\begin{array}{l}\text { - Hierarki tall } \\
\text { - Individual } \\
\text { - Span of control sempit } \\
\text { - Fungsional } \\
\text { - Static, stable, rigid } \\
\text { - Internal } \\
\text { - Control } \\
\text { - Hierarchical } \\
\text { - Berfokus pada profit } \\
\text { - Functoinal, division, matrix }\end{array}$ & $\begin{array}{l}\text { - Hierarki flat } \\
\text { - Team } \\
\text { - Span of control luas } \\
\text { - Integrasi, melibatkan setiap unit } \\
\text { - Dynamic, changing, flexible } \\
\text { - External } \\
\text { - Empowerment } \\
\text { - Networked } \\
\text { - Berfokus pada kepuasan pelanggan } \\
\text { - Network, celluler }\end{array}$ \\
\hline
\end{tabular}

Organisasi-organisasi yang sukses adalah organisasi yang mampu secara cepat mengalih strategi ke dalam tindakan, mengelola proses-proses intelligent, dan efisien memaksimumkan kontribusi dan komitmen karyawan dan menciptakan tanpa batas atau secara terus menerus. Menurut Ulrich (1998) melalui proses transformasi untuk mengembangkan kapabilitas organisasional, maka pentingnya pemikiran kembali peran baru sumber daya manusia.

\section{Perubahan Peran Sumber Daya Manusia}

Yeung, Brockbank \& Ulrich (1994), mengungkapkan bahwa di tengah-tengah transformasi perusahaan yang radikal, fungsi sumber daya manusia sedang mengalami transformasi dengan mengacu kepada tiga agenda baru sumber daya manusia sebagai katalisator perubahan: pengurangan biaya, kepuasan pelanggan, kebutuhan bisnis strategis. Reformasi fungsi sumber daya manusia mensyaratkan para profesional sumber daya manusia. Tabel 2 menjelaskan agenda perubahan fungsi sumber daya manusia. 
Tabel 2. Agenda Perubahan Fungsi Sumber Daya Manusia

\begin{tabular}{|l|c|}
\hline Katalisator Perubahan & Agenda/Taktik SDM \\
\hline - Cost Reduction & To reduce HR costs by: \\
& Share service \\
& Information system \\
& Outscoring \\
& \\
& To enhance quality of HR service by: \\
& Reengineering HR processes \\
& Making HR depts. as profit center \\
& Redefining line manager's role \\
& Developing self managed work teams \\
& Providing consulting services \\
& \\
& To focus on business objectives by: \\
& Functioning as strategic partners \\
& Facilitating organizational change \\
\hline
\end{tabular}

Kriteria untuk mendefinisikan peran baru sumber daya manusia menurut Conner \& Ulrich (1996) berbeda-beda, karena para penulis memandangnya dari sudut pandang atau fokus yang berbeda-beda. Fokus pada aktivitas (what do HR people do), fokus pada waktu (where do HR people spend time), fokus pada metaphors (what identify HR people have), dan fokus pada penciptaan nilai (what value HR people create).

Walker (1994) menunjukkan karakteristik peran baru sumber daya manusia sebagai suatu rangkaian peran yang dimulai dari support, service, consultating kepada leadership. Kebanyakan manajemen menekankan pada peran support dan service dibandingkan dengan peran consultating dan leadership.

Menurut Walker perusahaan cenderung menekankan pada peran consultating dan leadership. Conner \& Ulrich memberi definisi peran sumber daya manusia ini dengan memfokus pada aktivitas.

Menurut Schuler (1994) keterkaitan antara strategi sumber daya manusia dan strategi bisnis merupakan peran utama bagi sumber daya manusia dewasa ini. Dan Schuler tahun 1990 menggarisbawahi enam peran utama baru sumber daya manusia: business person, shaper of change, consultant to organization/partner to line, strategy formulator and impplementator, talent manager, asset manager, and cost controller (Conner \& Ulrich, 1996). Keenam peran ini berdasarkan kriteria definisi Conner dan Ulrich memfokus pada waktu. 
Ulrich (1998) menunjukkan peran sumber daya manusia melalui peran menjadi partner para manager senior dan lini dalam melaksanakan strategi atau strategic partner, menjadi ahli administrasi, menjadi employee champion dan agen perubahan. Gambar 1 menunjukkan model konseptual peran sumber daya manusia yang diusulkan Ulrich.

Gambar 1: Kerangka Kerja Peran Sumber Daya Manusia

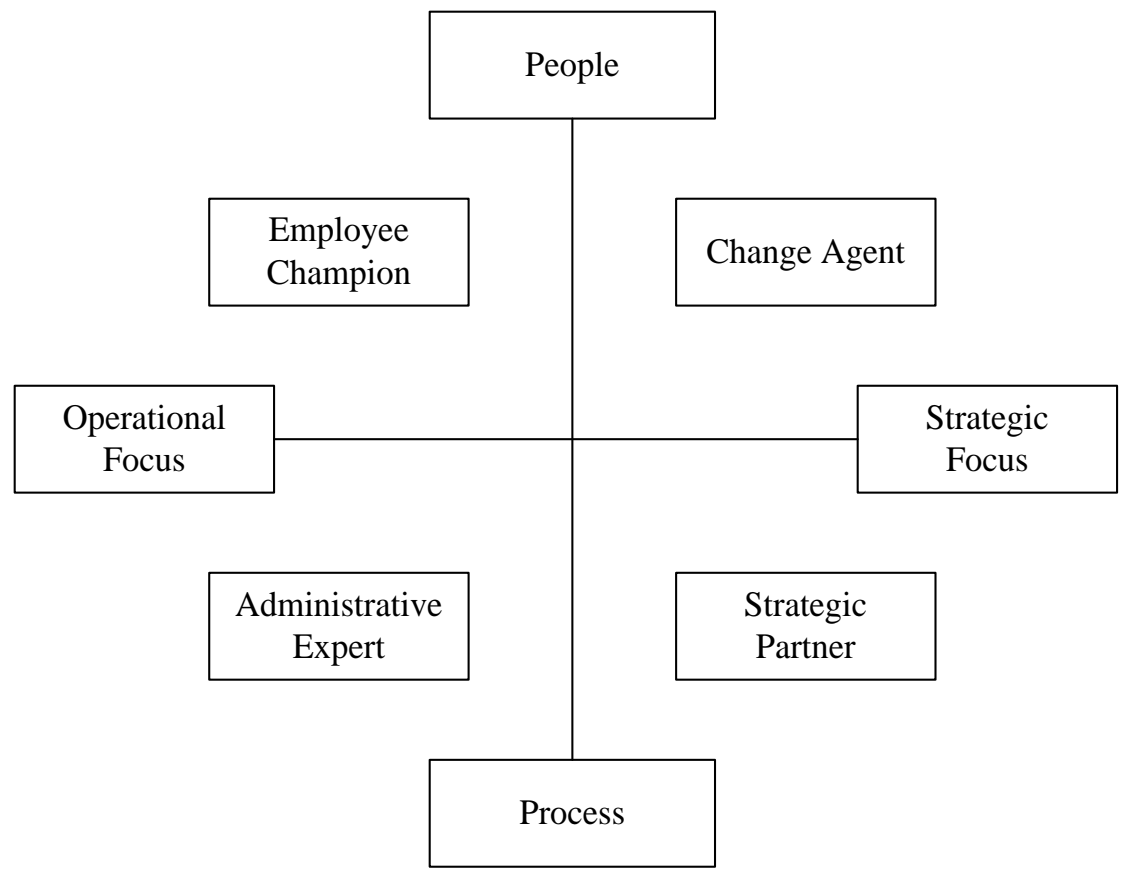

Sumber: Conner \& Ulrich, 1993: p.42

Berdasarkan pada beberapa pandangan penulis di atas, mencerminkan terjadinya pergeseran peran sumber daya manusia. Fungsi sumber daya manusia melalui peran barunya, berupaya mengembangkan kapabilitas organisasional untuk menciptakan keunggulan organisasi sebagai alat kompetitif dengan cara sebagai berikut.

\section{Pertama: Becoming a Partner in Strategy Execution}

Sumber daya manusia harus menjadi partner para manajer senior dan garis dalam melaksanakan strategi yang membantu untuk mengubah perancangan dari "conference room" ke "market place". A partner in strategy execution, oleh penulis lain menyebutkan sebagai strategic partner (Ulrich, 1998), consultant to organization parnter to line, strategy formulator (Schuler, 1994), business partner (Willey, 1992).

Untuk menciptakan kondisi ini akan melibatkan beberapa langkah sebagai berikut:

- Sumber daya manusia harus bertanggung jawab untuk menentukan atau mendefinisikan arsitektur organisasional 
- Sumber daya manusia harus bertanggung jawab untuk melaksanakan audit organisasional

- Sumber daya manusia harus mengidentifikasi metode untuk memperbarui bagian-bagian arsitektur organisasional yang membutuhkannya

- Sumber daya manusia harus mengadakan pemeriksaan tentang pekerjaannya sendiri dan menentukan prioritas yang jelas.

\section{Kedua: Becoming an Adminsitrative Expert}

Sumber daya manusia menjadi ahli dalam cara kerja yang diorganisir dan dilaksanakan untuk menghasilkan efisiensi administratif yang menjamin penekanan biaya dengan tetap mempertahankan kualitas. Dalam hal ini terjadinya pergeseran peran lama sebagai administrator ke peran baru sebagai administrative experts. Penulis lain menyebutkan administrative expert sebagai controller, auditor (Schuler, 19940.

Staf sumber daya manusia manusia harus memperbaiki efisiensi baik dalam fungsinya sendiri maupun organisasi seluruhnya. Keberhasilannya memperbaiki efisiensi akan membangun kredibilitas sumber daya manusia yang pada gilirannya akan menjadi mitra dalam pelaksanaan strategi. Di samping itu, sumber daya manusia juga harus mengumpulkan, mengkoordinasikan, menyebarkan informasi utama tentang pasar dan proses organisasional.

\section{Ketiga: Becoming an Employee Champion}

Sumber daya manusia harus menjadi champion bagi karyawan yang mewakili urusanurusan mereka terhadap manajemen senior dan meningkatkan kontribusi para karyawan melalui komitmen dan kemampuan mereka memberi hasil terhadap organisasi. An employee champion oleh penulis lain menyebutkan sebagai business person (Schuler, 1994), provider, canciliator, employee, advocate, facilitator (Wiley, 1992).

Dalam peran baru ini sumber daya manusia profesoinal harus memegang tanggung jawab untuk memastikan, bahwa para karyawan diikutsertakan dan memiliki komitmen serta memberi kontribusi sepenuhnya terhadap organisasi. Sumber daya manusia harus mengambil tanggung jawab untuk memberi orientasi dan pelatihan kepada manajemen garis tentang pentingnya moral karyawan yang tinggi dan bagaimana cara untuk mencapainya. Dalam hal ini fungsi sumber daya manusia memegang peran kritis dalam merekomendasi cara-cara untuk memperbaiki masalah-masalah moral karyawan. 
Dan juga peran sumber daya manusia harus menjadi suara karyawan dalam diskusidiskusi manajemen. Juga menawarkan kesempatan bagi pertumbuhan profesional dan personal serta menyediakan sumber yang membantu para karyawan untuk memenuhi tugas yang diemban.

\section{Keempat: Becoming a Change Agent}

Sumber daya manusia harus menjadi agen transformasi yang terus menerus yang membentuk proses dan kultur yang bersama-sama meningkatkan kapabilitas terhadap perubahan. A change agent, oleh penulis lain juga menyebutkan sebagai shaper of change (Schuler, 1994), innovator change agent (Wiley, 1992).

Peran baru sumber daya manusia bertanggung jawab membangun kemampuan organisasi untuk merangkul dan menggunakan kesempatan perusahaan. Dalam hal ini sumber daya manusia akan meyakinkan bahwa inisiatif perubahan yang berfokus pada kinerja teams, implementasi teknologi baru tertentu, dikembangkan dan disampaikan dengan cara yang tepat pada waktunya.

Peran baru sumber daya manusia juga meyakinkan bahwa pernyataan visi yang luas yang ditransformasikan ke dalam perilaku khusus, dengan membantu karyawan untuk memahami pekerjaan mana yang dapat mereka hentikan, mulai dari mempertahankan sehingga visi menjadi kenyataan. Peran sumber daya manusia sebagai agen perubahan juga berupaya mengganti resistance dengan resolve, planning dengan result dan fear of change dengan axcitement about its probabilities.

Sehubungan dengan pembahasan peran baru sumber daya manusia ini, Blackburn \& Rosen (1993), juga menyatakan bahwa untuk menjadi full partner, sumber daya manusia yang profesional harus menjadi ahli melalui kontribusi fungsinya. Hal ini berarti sumber daya manusia menjadi agen perubahan yang menuntun penilaian ulang berbagai praktik manajemen sekarang.

Drucker (1995) menyatakan bahwa staf sumber daya manusia akan bersama-sama manajemen lini dalam mengambil keputusan dan tindakan dan tidak sekedar saran. Hal ini berarti bahwa staf sumber daya manusia bukan bersama-sama unit bisnis untuk memahami situasi masing-masing dan orang yang terlibat serta mendukung para manajer secara aktif untuk mencapai perubahan yang diinginkan.

\section{Pengembangan Teknologi}


Salah satu ciri dunia yang paling menonjol dewasa ini dan yang diperkirakan terus berlanjut di masa yang akan datang ialah perkembangan ilmu pengetahuan dan teknologi yang sangat pesat. Bagi para manajer puncak perkembangan tersebut mempunyai ramifikasi yang luas dalam kegiatan mengelola perusahaan. Ramifikasi itu ada yang bersifat positif dan oleh karenanya melalui strategi yang tepat dapat dimanfaatkan, tetapi ada pula yang bersifat negatif dan harus dikenali agar dampaknya dapat dihilangkan atau paling sedikit dikurangi. Misalnya, perkembangan ilmu pengetahuan yang sangat pesat kemungkinan para manajer menggunakan instrumen ilmiah baru yang lebih ampuh dan tidak terus bergantung pada teori kuno yang sangat mungkin tidak mampu menyelesaikan bagi masalah baru yang dihadapi. Hal ini sangat penting karena seperti diketahui satu ilmu baru tumbuh dan berkembang memenuhi tuntutan kebutuhan masyarakat dalam arti bahwa ilmu yang sudah dikenal tidak ampuh lagi digunakan oleh pihak yang memerlukan.

Berkat perkembangan teknologi yang sangat pesat, dunia mengalami paling sedikit tiga jenis utama revolusi teknologi (Werther \& Davis, 1996) yaitu revolusi teknologi transportasi, revolusi teknologi komunikasi dan revolusi teknologi informasi. Revolusi teknologi transportasi telah mengubah "wajah" dunia dari satu planet raksasa menjadi hanya "satu desa global". Bahkan revolusi teknologi transportasi tersebut membuat seolah-olah manusia tidak lagi terikat pada hukum ruang dan waktu. Mobilitas manusia dan barang menjadi sangat tinggi berkat revolusi tersebut dan hal ini mempunyai implikasi yang sangat luas dalam mengelola suatu perusahaan.

Perkembangan teknologi komunikasi sudah sedemikian rupa sehingga sarana dan prasarana komunikasi gaya lama terasa sangat tidak memadai karena lambat, makan biaya yang tidak sedikit dan sering tidak efektif. Berbeda halnya dengan teknologi komunikasi mutakhir yang sangat cepat, terjadi tanpa distorsi, bersifat multimedia dan dengan "kecenderungan" biaya yang semakin rendah. Penggunaan telekomunikasi modern dengan berbagai alatnya membuat proses komunikasi berjalan dengan gaya yang sama sekali berbeda dengan masa lalu.

Perkembangan teknologi informasi berlangsung dengan kecepatan yang belum pernah dialami sebelumnya, dan komputer adalah primadonanya. Dari segi piranti kerasnya, perkembangan teknologi yang sangat pesat itu terlihat antara lain pada tersedianya komputer mulai dari main frame raksasa dengan kemampuan yang sangat tinggi dan beraneka ragam 
hingga personal computer yang sederhana. Bersamaan dengan perkembangan di bidang piranti keras terjadi pula perkembangan di bidang piranti lunak, aneka ragam program sudah diciptakan yang memungkinkan makin banyaknya jenis aplikasi komputer yang dapat dilakukan. Komputer telah merupakan satu hasil perkembangan teknologi mutakhir yang digunakan dalam banyak kegiatan perkantoran (Huczynski \& Buchanan, 1991).

Jika di masa lalu dalam perusahaan terdapat Electronic Data Processing Unit dengan brainware yang langka dan mahal, dewasa ini kebutuhan akan adanya satuan kerja seperti itu sudah lain sifat dan urgensinya. Kehadiran PC telah mengubah semua itu. Dalam pada itu ada hal lain yang harus diperhitungkan oleh para manajer yaitu bahwa usia satu generasi komputer cenderung makin pendek. Teknologi yang digunakan untuk rancang bangun suatu generasi komputer sangat cepat kadaluwarsa. Hal ini perlu mendapat perhatian bukan hanya dikaitkan dengan soal biaya, akan tetapi juga dengan kompetensi para anggota organisasi untuk memanfaatkannya.

Perubahan global mendorong terjadinya paradigma baru pada bidang ekonomi. Kemajuan dan pemanfaatan teknologi digital khususnya teknologi komunikasi dan informasi pada setiap kegiatan dan proses ekonomi menciptakan nuansa baru pada aspek organisasi, proses, manajemen, dan sumber daya manusia yang berbasis pengetahuan. Ekonomi baru yang berbasis pengetahuan (knowledge-based economy) bertolak pada aplikasi pengetahuan manusia (human know-how) pada setiap apa yang kita produksi dan bagaimana memproduksinya. Nilai tambah ekonomis semakin ditentukan dan diciptakan lebih banyak oleh otak daripada otot (by brain rather than brawn). Produk itu sendiri mempunyai kandungan (content) pengetahuan misalnya produk yang dilengkapi dengan teknologi digital seperti chip dan microprocessor.

Teknologi komunikasi dan informasi yang super cepat dan kerja jaringan yang memasuki "The Age of Networked Intelligence". Dengan microprocessors dan jalur kaca fiber mampu membawa manusia menembus dinding dan menyeberang ke planet untuk mengaplikasikan pengetahuan pada setiap aspek kehidupan ekonomi dan sosial. Dengan teknologi jaringan seperti internet dan internet dengan Worlds Wide Web (WWW) dapat memudahkan manusia berbagi informasi, berhubungan dan berkomunikasi dalam masyarakat global.

Menghadapi persaingan pasar, teknologi memegang peranan yang sangat penting, teknologi senantiasa berubah, merupakan basis pada perkembangan (Drejer \& Riis, 1999). 
Dengan demikian, bagi perusahaan yang akan masuk pada pergaulan global maka tidak ada pilihan lain kecil membuat persiapan dan mengadakan perubahan terhadap teknologi yang ada. Tanpa perubahan dan adaptasi yang dilakukan adalah sulit bagi perusahaan tersebut bersaing di tengah pasar yang sarat dengan persaingan.

\section{Menciptakan Suatu Organisasi Belajar}

Perubahan global telah mendorong perubahan keinginan pelanggan atas produk atau jasa yang dihasilkan. Mereka menghendaki produk dan jasa yang mereka beli adalah produk dan jasa yang sesuai dengan keinginan dan kebutuhan mereka. Produk dan jasa harus bermutu lebih baik, penyerahan lebih cepat, harga relatif murah dan bermanfaat. Oleh karena itu, perusahaan harus berupaya memenuhi permintaan ini dan mereka harus melakukan transformasi dan perbaikan mutu yang terus menerus, mengefektifkan semua sarana yang ada mencapai efisiensi yang tinggi dan mampu bersaing.

Menurut Brill (1997), perusahaan yang dapat bertahan dan bersaing dalam era pasar bebas dan abad ke-21 adalah perusahaan yang memiliki karakteristik sebab. Mempunyai misi dan visi yang jelas dan terarah, kegiatan proses dengan lintas fungsi dan struktur organisasi yang mendatar dengan pemberdayaan yang jelas. Mereka berorientasi global dan mempunyai jaringan yang luas. Memanfaatkan teknologi informasi dengan baik, berfokus bukan hanya untuk pemegang saham tetapi juga pada lingkungan.

Bentuk perusahaan akan lebih ramping dan lincah dalam penyesuaian pengaruh perubahan. Mereka berfokus pada dorongan pelanggan dengan penekanan pada mutu terpadu. Mereka memanfaatkan waktu seefisien mungkin pada setiap kegiatan dan proses. Mereka selalu inovatif dan menawarkan kewiraswastaan.

Dengan adanya pergeseran ini, diperlukan pembaruan kembali atas investasi pada sumber daya manusia berfokus pada kebijakan dan strategi baru yang merupakan alat motivasi baru. Modal manusia (human capital) akan dinilai kembali, dimana para pemimpin akan berbicara "core competence, competing on capability" atau keinginan mereka menjadi organisasi pembelajaran. Penemuan cara menilai dan mengukur modal manusia-keterampilan, kapabilitas dan know how merupakan langkah penting yang menjadi perhatian para pimpinan atas keberhasilan bawahan. Kebijakan seperti ini dapat memperbarui loyalitas, komitmen, dan 
produktivitas karyawan baik pria maupun wanita dalam organisasi sebagai upaya mereka berjuang melakukan pekerjaan, kemakmuran dan sejahtera dalam ekonomi global.

Fenomena ini perlu diperhatikan dalam melakukan perubahan dan transformasi di tempat kerja dan ini akan menjadi rambu-rambu bagaimana sebaiknya mengelola organisasi dan mempersiapkan angkatan kerja yang memiliki kompetensi yang sesuai dengan kebutuhan dan dapat mengisi kesempatan kerja yang terjadi.

Perspektif jabatan atau pekerjaan di abad ke-21 bagi perusahaan global oleh Mitrani, et al. (1995) dan Rhinesmith (1996), telah merinci kompetensi angkatan kerja yang akan datang sesuai dengan tingkat hierarki manajemen yaitu kompetensi para eksekutif adalah berpikir strategis, kepemimpinan atas perubahan dan manajemen hubungan. Para manajer memiliki kompetensi keluwesan pelaksanaan perubahan, saling pengertian antar pribadi, memberikan kewenangan dan pemberdayaan, bantuan atas kelompok dan portabilitas.

Seorang manajer yang ingin berhasil dalam era dunia yang berubah ini harus memiliki setidaknya lima keterampilan yaitu: (1) mengelola persaingan (managing competitiveness); (2) mengelola kompleksitas (managing complexity); (3) mengelola penyelarasan organisasi (managing organizational alignment); (4) mengelola perubahan organisasi (managing organizational change); dan (5) mengeloal tim multikultural (managing multicultural teams).

Sementara karyawan pelaksana memiliki keluwesan, selalu mencari informasi, motivasi dan kemampuan belajar, motivasi untuk berprestasi, bekerja pada tekanan waktu, bekerjasama dan berorientasi pada pelayanan terhadap pelanggan. Di Amerika calon karyawan pada jabatan terendah harus memiliki pendidikan setara dengan diploma dua dan diperkirakan bahwa suatu jabatan yang tadinya dijabat oleh lulusan perguruan tinggi dengan gelar master atau strata dua, tahun 2000, jabatan ini akan dipegang oleh orang yang bergelar strata tiga atau doktor.

Dengan gambaran jabatan dan pekerjaan tersebut di atas, maka kompetensi tenaga kerja yang diperlukan akan sangat tinggi baik kemampuan teknis, manajerial, maupun hubungan antar manusia. Mereka memangku jabatan tersebut dapat dikategorikan sebagai angkatan kerja bebasis pengetahuan dan elektronik (knowledge workers atau wired workers dan atau cyberspace workers) yang berkemampuan tinggi dalam memanfaatkan teknologi informasi dengan efektif, mengelola perubahan, persaingan dan multikultural. Para manajer yang dinamis, berwawasan luas, cerdas dan karismatik; para pelaksana memiliki kompetensi yang tinggi dan profesional dengan wawasan yang lebih luas serta berlandaskan pengetahuan. 
Mengacu pada kebutuhan industri dan antisipasi perubahan, khususnya perubahan teknologi di dunia kerja diperlukan learning organization (organisasi belajar). Organisasi belajar ditujukan guna mencari cara-cara baru untuk menanggapi dengan sukses dunia yang saling bergantung dan yang berubah (Dodgson, 1993) dan merupakan persyaratan mendasar untuk mempertahankan eksistensi (Kim, 1993).

Pemikiran ulang atas tujuan, proses dan penempatan kembali sumber-sumber yang ada pada sistem pendidikan, akan membawa suatu perubahan yang diharapkan dapat memenuhi dan mempercepat proses pembelajaran dan hubungannya dengan pekerjaan dan kehidupan sehari-hari.

Pembelajaran dalam ekonomi memunculkan enam tema (Tapcott, 1996): (1) increasingly work and learning are becoming the same thing; (2) learning becoming a life long challenge; (3) learning is shifting away from the formal school and universities; (4) some educational institution are working hard to reinvent themselves for relevance, but progress is low; (5) organizational consciousness is required to create learning organization; and (6) the new media can transform education, creating a working-learning infrastructure for the digital economy.

Suatu sistem pendidikan dan pelatihan yang berintegrasi penuh dengan teknologi dan informasi yang cepat akan dapat menjaga langkah percepatan perkembangan pengetahuan dan kemajuan teknologi yang terjadi hampir di semua bidang, termasuk bidang pembinaan sumber daya manusia.

\section{KESIMPULAN}

Globalisasi khususnya bidang ekonomi secara makro berpengaruh terhadap tatanan sistem perekonomian dan kelangsungan hidup maupun intensitas gerak dinamika setiap lembaga ekonomi. Sebagai akibat semakin berkembang kemajuan ilmu pengetahuan dan teknologi, terutama teknologi informasi dan komunikasi, maka batas-batas suatu wilayah yang secara fisik ternyata terpisah dapat dimungkinkan untuk ditembus. Pasar internasional juga telah diwarnai oleh pasar bebas yang penuh dengan persaingan yang ketat. Globalisasi telah menuntut peningkatan efisiensi, produktivitas yang tinggi dan pengelolaan sumber daya manusia yang efektif.

Bagi perusahaan yang akan bermain dalam era global tidak ada cara lain kecuali harus mengadakan pembenahan dan perubahan ke arah lebih efisien, pembenahan dan perubahan 
mana ditujukan agar perusahaan dapat bersaing dengan sesama pelaku bisnis dalam merebut pasar. Perubahan struktural organisasi secara internal tidak dapat dielakkan, demikian juga perlakuan terhadap sumber daya manusia yang disesuaikan dengan kemajuan teknologi merupakan sesuatu yang menjadi mutlak dalam upaya mengelola perusahaan dan mengadaptasi setiap perusahaan yang makin berlanjut.

\section{DAFTAR PUSTAKA}

Allers, B.B., Snow C.C. and Miles, E.R. 1996. Characteristics of The Conceptualization and Measurement Careers in the 21 $1^{\text {st }}$ Century. Academy of Management Executive. 10 (4) : 1727.

Bassi, L.J., Benson, G., and Cherry. 1996. Polition Yourself for the Future, ASTD: Alexandria.

Blackburn, R., and Rosen, B. 1993. Total Quality and Human Resources Management: Leson Learned from Baldrige Award-Winning Companies, Academy of Management Executive, 7(3): 49-65.

Brill, P.L., and Worth, R. 1997. The Four Levels of Corporate Change. New York: Amacom.

Conner, J. and Ulrich, D. 1996. Human Resource Role: Creating Value, Not Rhetoric. Human Resource Planning. 38-49.

Davis, K. and Werther, Jr. 1996. Human Resources and Personnel Management. Singapore: McGraw Hill, Co.

Drejer, A., and Riis, J.O. 1999. Competence Development and Technology: How Learning and Technology Can Be Meaningfully. Technology, 19 (10): 631-644.

Drucker, P.F. 1995. Managing in Time of Great Change. New York: Truman Talley Books.

Dodgson, M. 1993. Organizational Learning: A Review of Some Literatures. Organization Series, Vol 14, No. 3.

Huczynski, A. and Buchanan, D. 1991. Organizational Behavior. London: Prentice Hall International Ltd.

Kim, D.H. 1993. The Link Between Individual and Organizational Learning, Sloan Management Review. Autumn: 37.

McDermott, L. 1996. OK, We Need to Redesign, So Where Do We Start, Journal for Quality and Participation, March, 52-56.

Mitrani, A., et al. 1995. Manajemen Sumber Daya Manusia Berdasarkan Kompetensi, (Terjemahan), Jakarta: Grafiti.

Rhinesmith, S.H. 1996. A Manager Guide to Globalization, ASTD, Alexandria.

Robbins, S.P. 1996. Perilaku Organisasi (Terjemahan), Jakarta: PT. Bhuana Ilmu Populer.

Ulrich, D. 1998. A New Mandate for Human Resource, Harvard Business Review, JanuaryFebruary, 124-234. 
Walker, W.J. 1994. Integrating the Human Resource Function With Business. Human Resource Planning. 17(2): 59-77.

Wiley, C. 1992. A Comprehensive View of Roles for Human Resource Manager in Industry Today, Industrial Management, 27-29.

Yeung, A., Brockbank, W. and Ulrich, D. 1994. Lower Cost, Higher Value: Human Resource Function in Transformation, Human Resource Planning, 17 (3): 1-16. 